\title{
What the radiologist needs to know about the diabetic patient
}

\author{
Athanasios E. Raptis • Konstantinos P. Markakis • Maria C. Mazioti • \\ Sotirios A. Raptis • George D. Dimitriadis
}

Received: 31 July 2010 /Revised: 16 November 2010 /Accepted: 13 January 2011 / Published online: 2 February 2011

(C) European Society of Radiology 2011

\begin{abstract}
Diabetes mellitus (DM) is recognised as a major health problem. Ninety-nine percent of diabetics suffer from type $2 \mathrm{DM}$ and $10 \%$ from type 1 and other types of DM. The number of diabetic patients worldwide is expected to reach 380 millions over the next 15 years. The duration of diabetes is an important factor in the pathogenesis of complications, but other factors frequently coexisting with type $2 \mathrm{DM}$, such as hypertension, obesity and dyslipidaemia, also contribute to the development of diabetic angiopathy. Microvascular complications include retinopathy, nephropathy and neuropathy. Macroangiopathy mainly affects coronary arteries, carotid arteries and arteries of the lower extremities. Eighty percent of deaths in the diabetic population result from cardiovascular incidents. DM is considered an equivalent of coronary heart disease (CHD). Stroke and peripheral artery disease (PAD) are other main manifestations of diabetic macroangiopathy. Diabetic cardiomyopathy (DC) represents another chronic complication that occurs independently of CHD and hypertension. The greater susceptibility of diabetic patients to infections completes the spectrum of the main consequences of DM. The serious complications of DM make it essential for physicians to be aware of the screening guidelines, allowing for earlier patient diagnosis and treatment.
\end{abstract}

A. E. Raptis $(\bowtie) \cdot$ K. P. Markakis • M. C. Mazioti · S. A. Raptis ·

G. D. Dimitriadis

2nd Department of Internal Medicine-Propaedeutic,

Research Institute and Diabetes Centre, University of Athens

Medical School, Attikon University Hospital,

1 Rimini Str,

12462 Haidari, Greece

e-mail: atraptis@med.uoa.gr

S. A. Raptis

Hellenic National Center for Research, Prevention and Treatment of Diabetes Mellitus and its Complications (H.N.D.C.),

Athens, Greece
Keywords Diabetes mellitus · Complications · Imaging · MRI $\cdot$ CT $\cdot$ PET $\cdot$ Ultrasound

\section{Introduction}

Diabetes mellitus (DM) is a major health and economic problem. It is a chronic epidemic disease occurring across the world with multiple complications. The size of the diabetic population worldwide, according to the International Diabetes Federation (IDF), is expected to consist of 380 millions people by 2025 [1]. The global cost of diabetes medication and its complications was calculated for 2007 to be 232 billion dollars.

\section{Definition and classification of DM}

According to the American Diabetes Association (ADA) and the World Health Organisation (WHO), DM describes a metabolic disorder of multiple aetiology, characterised by chronic hyperglycaemia with disturbances of carbohydrate, fat and protein metabolism resulting from defects in insulin secretion, insulin action, or both $[2,3]$. The criteria that are now in use for the diagnosis of DM recommended by the ADA in 2010 are shown in Table 1 [2].

The current classification of DM distinguishes four categories of diabetes [2]. The main types are: type $2 \mathrm{DM}$, formerly called non-insulin-dependent DM (NIDDM) or adult-onset DM, is observed in $90 \%$ of the diabetic population and is characterised by insulin resistance in peripheral tissues and an insulin secretory defect of the beta cell. This form of DM develops gradually and is occult at earlier stages so that the onset of diabetes usually precedes the clinical manifestations and diagnosis for many years. The 
Table 1 Diagnostic criteria of diabetes

1. Glycated haemoglobin $(\mathrm{HbA} 1 \mathrm{c}) \geq 6.5 \%$

or

2. Fasting plasma glucose $(\mathrm{FPG}) \geq 126 \mathrm{mg} / \mathrm{dl}(7.0 \mathrm{mmol} / \mathrm{l})$

or

3. Two hours plasma glucose $\geq 200 \mathrm{mg} / \mathrm{dl}(11.1 \mathrm{mmol} / \mathrm{l})$ during an oral glucose tolerance test (OGTT), using $75 \mathrm{~g}$ anhydrous glucose dissolved in water.

4. If a person appears the classic symptoms of hyperglycaemia (polyuria, polydipsia, polyphagia, weight loss and blurred vision) or acute consequences of hyperglycaemia (ketoacidosis, non-ketotic hyperosmolar syndrome), one random plasma glucose $\geq 200 \mathrm{mg} / \mathrm{dl}$ (11.1 mmol/l) is enough for the diagnosis

remaining $10 \%$ includes mainly patients with type $1 \mathrm{DM}$ and also some other less frequent types such as gestational diabetes, drug-induced diabetes (thiazides, glucocorticoids, $\beta$-adrenergic agonists, etc.) and MODY (maturity-onset diabetes in youth), which is characterised by genetic defects [2].

Besides diabetes, two other relative pathological situations are recognised: pre-diabetes and metabolic syndrome. Prediabetes is the state in which blood glucose levels are higher than normal, but not high enough to be diagnosed as overt diabetes. Subjects with pre-diabetes are at high risk of future development of DM [2]. Pre-diabetes is defined by the ADA as either impaired fasting glucose (IFG) and/or impaired glucose tolerance (IGT; Table 2). There is also a strong relation between DM and metabolic syndrome, which is a cluster of risk factors for cardiovascular disease (CVD) and diabetes. The current definition for the metabolic syndrome is shown in Table 3 [4]. Metabolic syndrome represents a powerful predictor of type $2 \mathrm{DM}$, because insulin resistance, which is the most important disorder of the syndrome, frequently precedes the onset of diabetes and thus it confers a fivefold increase in risk for type 2 DM [4]. Patients with the metabolic syndrome are at twice the risk of developing CVD over the next 5-10 years compared with individuals without the syndrome.

\section{Prevalence}

DM affects almost $6 \%$ of the world's population, but its incidence increases every year [5]. The prevalence of diabetes is expected to increase by $54 \%$ until 2030. A $69 \%$ increase in the number of adults with type $2 \mathrm{DM}$ in developing countries is estimated to occur between 2010 and 2030, and the biggest proportion of this increase will concern persons aged between 40 and 60 years. The respective increase in developed countries is estimated to be $20 \%$ and that mostly concerns people over 60 years of age. The likeliest explanations for these trends include ageing, urbanisation and the adoption of a western lifestyle leading to obesity and a sedentary life, and also the improvement of longevity of people with diabetes as a result of better health care improvement [5-7]. Type 1 DM still has the biggest prevalence among children, but in recent years this has changed because more and more children are becoming obese. The recent WHO report on Diet, Nutrition and the Prevention of Chronic Diseases placed obesity at the top of the public health agenda as a major risk factor [6]. Rising levels of obesity and type 2 DM in children are cause for concern worldwide $[7,8]$.

\section{Risk factors}

Lifestyle plays a crucial role in the development of type 2 DM. There is certainly a genetic predisposition for type 2 $\mathrm{DM}$, but the presence of multiple risk factors is leading to the epidemic of the twenty-first century. Risk factors are distinguished as non-modifiable and modifiable ones. The first category includes the age (persons over 45 years old), the family history of type $2 \mathrm{DM}$ and the ethnicity [9]. Also, a history of gestational DM is an important risk factor, because it places women at increased risk of the later development of type 2 DM [4]. Fortunately, lifestyle modifications like healthy diet, physical activity and breast-feeding can prevent it [10]. On the other hand, there are modifiable risk factors, like obesity $(\mathrm{BMI} \geq 30)$ and physical inactivity, which are considered the main non-

Table 2 Diagnostic criteria of pre-diabetes

IFG: Fasting plasma glucose $\geq 100 \mathrm{mg} / \mathrm{dl}(6.1 \mathrm{mmol} / \mathrm{l})$ and $\leq 125 \mathrm{mg} / \mathrm{dl}(6.9 \mathrm{mmol} / \mathrm{l})$ during an oral glucose tolerance test (OGTT), using $75 \mathrm{~g}$ anhydrous glucose dissolved in water.

IGT: Two hours plasma glucose $\geq 140 \mathrm{mg} / \mathrm{dl}(7.8 \mathrm{mmol} / \mathrm{l})$ and $\leq 199 \mathrm{mg} / \mathrm{dl}(11.0 \mathrm{mmol} / \mathrm{l})$ during an oral glucose tolerance test (OGTT), using $75 \mathrm{~g}$ anhydrous glucose dissolved in water 
Table 3 Criteria for diagnosis of metabolic syndrome

Necessary at least three of the below:

1) Waist circumference $\geq 94 \mathrm{~cm}$ for men and $\geq 80 \mathrm{~cm}$ for women (IDF recommendation) or $\geq 102 \mathrm{~cm}$ for men and $\geq 88 \mathrm{~cm}$ for women (AHA/ NHLBI recommendation).

2) Triglyceride levels $\geq 150 \mathrm{mg} / \mathrm{dl}(1.7 \mathrm{mmol} / \mathrm{l})$.

3) HDL cholesterol levels $<40 \mathrm{mg} / \mathrm{dl}(1.0 \mathrm{mmol} / \mathrm{l})$ for men and $<50 \mathrm{mg} / \mathrm{dl}(1.3 \mathrm{mmol} / \mathrm{l})$ for women.

4) Systolic blood pressure $\geq 130 \mathrm{mmHg}$ and/or diastolic blood pressure $\geq 85 \mathrm{mmHg}$.

5) Fasting plasma glucose (FPG) $\geq 100 \mathrm{mg} / \mathrm{dl}(5.6 \mathrm{mmol} / \mathrm{l})$.

IDF International Diabetes Federation, AHA/NHLBI American Heart Association/National Heart Lung Blood Institute

genetic determinants of the disease [2]. In addition, previously identified pre-diabetes, which includes IFG or IGT, may progress to type 2 DM [4]. Finally, dyslipidaemia [11], hypertension $[12,13]$ and the coexistence of the components of metabolic syndrome, such as central obesity, increase the risk of the future development of diabetes [4].

\section{Diabetic complications}

The classic symptoms of hyperglycaemia include polyuria, polydipsia, polyphagia, weight loss and blurred vision, but it has to be underlined that it may not be present for years in type $2 \mathrm{DM}$. As the prevalence of DM increases, diabetesrelated mortality also increases. The multimorbidity of diabetics increases mortality in all age groups [14].

Earlier exposure to hyperglycaemia has the potential to accelerate the progression and severity of vascular complications. Future generations will be burdened with the complications of diabetes at the peak of their productivity. The multimorbidity of the diabetic population is increased because of the presence of acute and chronic complications, the coexistence of hypertension and dyslipidaemia and, moreover, the high incidence of infections.

Diabetic complications are distinguished as either acute or chronic (Table 4). Acute complications resulting from acute metabolic derangement and severe hyperglycaemia include ketoacidosis and the non-ketotic hyperosmolar state [15]. Hypoglycaemia resulting from the use of insulin and oral antidiabetic agents is also an acute complication.

DM may affect almost every organ and system. Chronic complications include microvascular and macrovascular ones. Microvascular complications include retinopathy, nephropathy and neuropathy, while macrovascular include coronary heart disease (CHD), peripheral artery disease (PAD), cerebrovascular incidence and erectile dysfunction. Duration of diabetes is an important factor in the pathogenesis of these late complications. Other concomitant risk factors such as hyperglycaemia, hypertension, smoking and hyperlipidaemia, are involved in the progression of such complications. Diabetic cardiomyopathy represents another chronic complication, developing independently of CHD and hypertension. Finally, the greater susceptibility of diabetic patients to infections completes the spectrum of the main consequences of DM.

\section{Microvascular complications}

A continuous relation exists between glycaemic control and the incidence and progression of microvascular complications. Hypertension and smoking also have an adverse effect on microvascular outcomes. There is evidence that strict glucose control reduces the development and progression of microvascular complications [16-18].

\section{Diabetic nephropathy}

Diabetic nephropathy (DN) is the most common cause of endstage renal failure in the western world [19, 20]. It is defined as the presence of persistent proteinuria $(>0.5 \mathrm{~g} / 24 \mathrm{~h})$, and declining glomerular function in the absence of urinary tract infections, other renal disease, or heart failure. The annual incidence of diabetic nephropathy rises rapidly over the first 15-20 years of diabetes to decline sharply afterwards. DN

Table 4 Main diabetic complications

\begin{tabular}{ll}
\hline Acute & Ketoacidosis \\
& Non-ketotic hyperosmolar state \\
& Hypoglycaemia due to oral antidiabetic agents or insulin \\
Chronic $\quad$ Macroangiopathy $\rightarrow$ coronary heart disease \\
stroke \\
peripheral artery disease \\
Microangiopathy $\rightarrow$ diabetic nephropathy \\
diabetic retinopathy \\
diabetic neuropathy \\
Diabetic cardiomyopathy \\
Increased susceptibility to infections
\end{tabular}


affects up to $35 \%$ of type 1 diabetic patients and a smaller proportion of type 2 diabetic patients of Caucasian origin. However, because of the higher prevalence of type 2 diabetes, $50 \%$ of diabetic patients in renal replacement treatment programs have type 2 diabetes [20]. The mortality and morbidity of diabetic patients with end-stage renal disease (ESRD) are greater than those of patients with other causes of ESRD related to concomitant systemic disorders, especially coronary artery and cerebrovascular disease.

Diabetic nephropathy follows a well-outlined clinical course, starting with microalbuminuria (elevation of excretion of albumin in the urine, above what is the normal nondiabetic range, which goes up to $20 \mathrm{mg} / \mathrm{ml}$ ), through proteinuria, azotaemia and culminating in ESRD [21].

The earliest morphological abnormality in diabetic nephropathy is the thickening of the glomerular basement membrane and expansion of the mesangium due to accumulation of extracellular matrix. A stage of glomerular hyperfiltration and hypertrophy precedes the glomerular sclerosis and the deterioration of the glomerular filtration rate [22, 23]. Renal ultrasound reveals a normal to increased kidney size at the initial stage of hyperfiltration, while later at the progression of renal failure kidneys are decreased or shrunken with decreased thickness of the parenchyma. According to ADA recommendations an annual assessment of urine albumin excretion has to be performed in type 1 diabetic patients with diabetes duration of 5 years and in all type 2 diabetic patients, starting at diagnosis [24].

Beyond hyperglycaemia, another crucial factor for the progression of DN is arterial hypertension. The reninangiotensin-aldosterone system (RAAS) plays an important role in modulating the presence of microalbuminuria. RAAS-directed antihypertensive agents, including angiotensin converting enzyme (ACE) inhibitors, angiotensin II receptor blockers (ARBs) and renin inhibitors, have been demonstrated to have renoprotective effects [23, 25-28].

It has to be emphasised that a particularly important concern in diabetic patients, especially those with underlying renal insufficiency, is nephrotoxicity resulting from contrast agents used in imaging studies such as computed tomography (CT) or digital subtraction angiography (DSA). Clinical manifestations range from a mild and reversible impairment of the glomerular filtration rate to renal failure requiring haemodialysis. Special care should be taken in patients taking the oral hypoglycaemic agent metformin. Metformin accumulation caused by renal insufficiency can result in lactic acidosis, which is a serious and potentially fatal complication [29].

\section{Diabetic retinopathy}

Diabetic retinopathy (DR) is the leading cause of blindness in people of working age $[30,31]$. Blindness results from progressive retinopathy and macular oedema. DR is classified into two stages, non-proliferative DR (NPDR) and proliferative DR (PDR) [32]. The duration of DM and the degree of glycaemic control are mostly related to the development of DR. NPDR is usually demonstrated late in the first decade of the disease. It is characterised by the appearance of retinal vascular microaneurysms, exudates and blot haemorrhages. NPDR can progress to the more severe PDR. Neovascularisation is the hallmark of PDR. The newly formed vessels are prone to rupture leading to vitreous haemorrhage and subsequent fibrosis and retinal detachment. The prevalence of DR reaches $80 \%$ among patients with 20 or more years' duration of type 1 DM [33]. As type 2 DM usually remains unrecognised for years, a significant percentage of patients, ranging from $7 \%$ up to $38 \%$, already have DR at the time of diagnosis $[17,34]$. DR usually coexists with the other types of diabetic microangiopathy [32]. Patients with overt diabetic nephropathy are almost certain to have DR. According to the recent ADA guidelines, patients with type 1 DM should have an initial dilated and comprehensive eye examination by an ophthalmologist within 5 years of the onset of disease, while patients with type $2 \mathrm{DM}$ should have an initial evaluation shortly after the diagnosis of DM [24].

\section{Diabetic neuropathy}

Neuropathy is a common disorder in diabetic patients. It results from several pathways of metabolic insult but also microangiopathy sometimes contributes to its development [35]. Besides the duration of diabetes and poor glycaemic control, other factors such as higher body mass index, smoking, hypertension, and raised plasma cholesterol and triglyceride levels are associated with the incidence of neuropathy [36]. It manifests as polyneuropathy, mononeuropathy and/or autonomic neuropathy. The most common form of diabetic neuropathy is chronic sensorimotor distal symmetric polyneuropathy, which affects $30-50 \%$ of diabetic patients [37]. It is often asymptomatic, particularly at the beginning. The most frequent presentation of distal symmetric polyneuropathy is distal sensory loss, while other symptoms include burning pain, paraesthesiae, hyperaesthesiae and deep aching pain. The symptoms are typically located in the feet and lower limbs and neuropathic pain is usually worse at night. Patients suffering from distal symmetric polyneuropathy are at high risk of foot ulceration and subsequent amputation. Another complication associated with the loss of pain sensation, proprioception and muscular reflexes that regulate joint movement is Charcot neuroarthropathy (CN) [38]. CN almost exclusively affects the foot and it is characterised by progressive cartilage and bone damage resulted from repeated trauma due to the absence of 
the above-mentioned protective mechanisms. Initially, Charcot neuroarthropathy presents with a warm, swollen and painful foot, while at a more advanced stage numerous dislocations and fractures lead to severe deformity of the foot accompanied by severe disability. The plain X-ray is often impressive, while radionucleotide imaging and particularly magnetic resonance imaging (MRI) can help in the diagnosis and the differentiation from osteomyelitis, which is sometimes difficult. Peripheral mononeuropathies occur less frequently and mainly involve medial, ulnar, radial and common peroneal nerves [35]. Cranial neuropathies are extremely rare. Similarly, diabetic neuropathy rarely manifests as polyradiculopathy involving intercostal, truncal, or lumbar plexus, resulting in pain over the thorax, abdomen, or in the thigh and the hip respectively [15]. In the latest cases, a rare manifestation called diabetic amyotrophy can occur, characterised by weakness and atrophy in the proximal thigh muscles.

Diabetic autonomic neuropathy is frequent and can affect multiple systems, including cardiovascular, gastrointestinal and genitourinary. Concerning the cardiovascular system, the major clinical manifestations of diabetic autonomic neuropathy include resting tachycardia, exercise intolerance and orthostatic hypotension [35]. Moreover, silent myocardial ischaemia and sudden death have been attributed to diabetic autonomic neuropathy. Gastroparesis, constipation or diarrhoea, bladder dysfunction and erectile dysfunction are the most common types of the impairment of gastrointestinal and genitourinary systems. Diabetic autonomic neuropathy may also reduce the patient's ability to sense hypoglycaemia, thereby subjecting patients to the risk of severe hypoglycaemia.

\section{Diabetic cardiomyopathy}

The prevalence of heart failure (HF) is particularly increased in diabetic patients [39]. Furthermore, the likelihood of developing heart failure following a myocardial infarction is increased in diabetic patients [40]. Diabetes also represents a powerful risk factor for death among patients with established HF [41]. In the Framingham study, after adjustment for age, blood pressure, cholesterol level, obesity and history of CHD, the risk of congestive HF in diabetic males was over twice that of non-diabetic subjects, while in women the presence of diabetes entailed a more than fivefold increase in the risk of congestive HF [42]. It has been accepted that besides the increased prevalence of CHD and the increased likelihood of hypertension among diabetic patients there is also a distinct clinical entity called diabetic cardiomyopathy (DC). DC is now considered a common complication of type $1 \mathrm{DM}$ and type $2 \mathrm{DM}$. DC is defined as a primary disease process that develops secondary to metabolic insult, occurring independently of $\mathrm{CHD}$ and hypertension and leading to ventricular dysfunction [43]. The main feature of DC is the adverse myocardial remodelling, resulting in concentric left ventricular hypertrophy and leads to the development of a stiffened ventricle with diastolic dysfunction that progresses to diastolic HF or otherwise called HF with preserved ejection fraction. The impairment of diastolic function is the predominant clinical feature of DC and typically precedes systolic left ventricular dysfunction in diabetic patients. Myocyte hypertrophy, capillary basement membrane thickening and interstitial fibrosis are the prominent histological features of DC [44]. Diagnostic techniques currently used to detect the presence of DC include echocardiography and cardiac MRI [43, 45]. Echocardiography is currently the most frequently used method for the measurement of left ventricular wall thickness and pulse-wave Doppler echocardiography is the most practical method for the assessment of diastolic function. Cardiac MRI is considered the "gold standard" for measuring left ventricular mass. However, its use is mainly limited to research. The use of gadolinium allows the assessment of myocardial fibrosis (late gadolinium enhancement), while MR spectroscopy is another emerging research tool allowing the measurement of myocardial triglyceride content, which is a novel field of research concerning the diagnosis and the pathogenesis of DC [46, 47].

\section{Macrovascular diabetic complications}

There is a growing epidemic of atherosclerotic complications particularly concerning the type 2 diabetic population [48]. Macroangiopathy in diabetic patients progresses rapidly and affects multiple organs. Coronary arteries, extracranial carotid arteries and arteries of the lower extremities are mainly affected. The clinical expressions of diabetic macroangiopathy include CHD, PAD, stroke and erectile dysfunction. The coexistence of established risk factors for CHD such as hypertension, dyslipidaemia and obesity in type 2 diabetics further increases the prevalence of CVD [49]. Atherosclerosis is four times more common in patients with diabetes than in the nondiabetic population [50]. Eighty percent of deaths in the diabetic population result from cardiovascular incidents [51]. Seventy-five percent of these deaths are caused by $\mathrm{CHD}$ and the other $25 \%$ is due to stroke and PAD.

\section{DM as a CHD equivalent}

In the Framingham study mortality from CHD among type 1 diabetics was approximately four-times higher than that seen in non-diabetics [52]. In a meta-analysis of 37 prospective studies, which enrolled over 400,000 people 
the rate of fatal CHD was 3.5-times higher in the type 2 diabetic population in comparison with non-diabetics [53]. In the Multiple Risk Factor Intervention Trial (MRFIT), the diabetic population had a risk of CHD death more than three-times higher than that of the non-diabetic population for every age and ethnic group even after adjustment for established risk factors such as age, serum cholesterol level, systolic blood pressure and smoking [54]. The presence of diabetes also results in worse outcomes during the acute phase of myocardial infarction (MI), as well as in long-term follow-up [48]. In a Finnish study, diabetes increased the 28 -day mortality after an MI by $58 \%$ [55]. In a six-nation study that enrolled patients with unstable angina and non-Qwave MI, the OASIS registry, diabetes was independently associated with a $57 \%$ increase in the risk of death [56]. In another study the 5-year mortality rate after an MI in diabetic patients was more than double that of non-diabetic patients [57]. Diabetic patients without previous MI exhibit the same risk of subsequent acute coronary events as non-diabetic patients with a history of previous MI [58]. The studies mentioned above are representative of a large amount of data that have led to the establishment of DM as a CHD equivalent mandating aggressive anti-atherosclerotic management $[59,60]$. The outcomes of revascularisation procedures, either percutaneous coronary revascularisation or bypass angioplasty revascularisation, are also less favourable in diabetic patients $[61,62]$. Invasive methods such as coronary angiography and intravascular ultrasound are the "gold standards" for the diagnosis of CHD, while in the recent years new non-invasive methods such as positron emission tomography (quantitative measurement of blood flow and myocardial vitality), MRI (morphology and perfusion) and CT (calcium score and morphology) have been proven valuable research tools, with $\mathrm{CT}$ also becoming an emerging technique in clinical practice [63-65].

\section{DM and stroke}

The CV mortality in the diabetic population is high due to the coexistence of CHD and cerebrovascular disease. In the MRFIT cohort, diabetic patients had a threefold increased likelihood of developing a stroke [54]. Particularly among subjects younger than 55 years, the risk of stroke is increased more than tenfold in diabetic patients [66]. Diabetes also increases stroke-related mortality [67], while the risk of dementia following a stroke is increased by threefold [68]. Digital subtraction angiography (DSA) is still considered the "gold standard" for assessment of carotid stenosis, but it has now mostly been replaced by non-invasive techniques, especially Doppler ultrasound and also CT angiography and MR angiography [69]. Beyond the estimation of luminal stenosis, there is increasing interest in the assessment of plaque quality. The differentiation of high-risk, vulnerable carotid plaques from stable plaques is an emerging criterion for the identification of high-risk patients who need to undergo revascularisation, but also for the choice between endarterectomy and carotid artery stenting as there are data indicating that patients with vulnerable plaque are at increased risk of stroke in carotid artery stenting [70, 71]. The association between the presence of diabetes and the formation of vulnerable plaques is not yet elucidated, but a recent study concerning coronary atherosclerosis assessed by intravascular ultrasound reported a greater proportion of vulnerable plaques among diabetic patients compared with non-diabetic patients $(21.6 \%$ vs $13.6 \%)$ [72]. In addition to B-mode ultrasound, which is the widely used technique for the identification of vulnerable plaques, carotid MRI, multidetector-row $\mathrm{CT}$ and nuclear imaging techniques such as $\left({ }^{18} \mathrm{~F}\right)$ fluoro-glucose $\left({ }^{18} \mathrm{~F}\right.$-FDG) positron emission tomography (PET) are promising methods for a more accurate evaluation of plaque quality $[69,71]$.

\section{Screening for subclinical atherosclerosis}

Endothelial dysfunction is probably the first demonstration in the development of atherosclerosis that can be clinically assessed. Numerous studies suggest the impairment of endothelial dysfunction and the subsequent development of arterial stiffness as premature events in the evolution of atherosclerosis and that diabetes impair endotheliumdependent vasodilatation before the formation of atheroma [48]. Several epidemiological studies have revealed that endothelial dysfunction predicts future cardiovascular events [73]. A significant amount of data has demonstrated that impairment of glucose homeostasis leads to endothelial dysfunction and arterial stiffness. DM but also IFG and IGT are strongly associated with the presence of endothelial dysfunction and arterial stiffness [74]. Non-invasive techniques using ultrasound have developed to assess endothelial dysfunction. These include the measurement of flowmediated dilatation (FMD) or the nitrate-induced dilatation of the brachial artery, the measurement of carotid-femoral pulse wave velocity (PWV) and techniques of pulse wave analysis recording the radial pulse wave (PWA) [73]. These methods are widely used in research and they are valuable for assessing the potential anti-atherogenic efficacy of treatment options. However, the variability of the results in terms of absolute values between different laboratories and the diversity of methods in use have not yet permitted these techniques to be integrated into everyday clinical practice. The most validated of these methods is the measurement of PWV, and the European Society of 
Hypertension and the European Society of Cardiology define values above $12 \mathrm{~m} / \mathrm{s}$ to be a marker of subclinical cardiovascular damage [75]. On the other hand, measurement of the combined thickness of the intima and media of the carotid artery (CIMT or simply IMT as it is more frequently mentioned) is widely used not only in research but also in clinical practice. The increase in IMT is considered to be a phenotype of early atherosclerosis [76]. Several large observational studies have demonstrated IMT to be a strong predictor of future cardiovascular events [77]. As measurement of IMT by ultrasound is also a simple, non-invasive and inexpensive test, IMT is an emerging strong risk factor for cardiovascular disease. The European Society of Hypertension and the European Society of Cardiology define values of IMT above $0.9 \mathrm{~mm}$ to indicate subclinical cardiovascular damage [75]. Common carotid artery (CCA) IMT $>0.87 \mathrm{~mm}$ and internal carotid artery (ICA) IMT $>0.90 \mathrm{~mm}$ were found to be associated with an increased risk of cardiovascular disease [76]. IMT has been used for the evaluation of the presence of early atherosclerosis and also for the assessment of the efficacy of several treatments such as the administration of lipid-lowering agents $[78,79]$. Not only type $2 \mathrm{DM}$, but also IGT are associated with an increase in IMT [78]. An increasing number of studies use IMT measurement to reclassify patients into higher or lower risk categories [80].

\section{DM and PAD}

The development of PAD is two- to fourfold more common among diabetic patients [81]. The incidence and extent of PAD correlate with the duration and severity of DM [82]. The coexistence of hypertension, dyslipidaemia and central obesity, which is common in diabetic patients, contributes to the development of PAD [83]. There is a strong association with cardiovascular morbidity [84]. PAD results in disability with serious social consequences and may require surgery. The clinical presentation of PAD typically includes intermittent claudication, which can progress to resting pain, ulceration and gangrene. The stage of intermittent claudication is characterised by pain in the legs after walking a certain distance. The characteristic symptom in critical ischaemia stage is resting pain, which leads to severe disability. Gangrene is the end stage of PAD and amputation is inevitable. Among patients with PAD, diabetic patients have worse arterial disease and poorer outcome than non-diabetic patients. The impairment of circulation frequently combined with impaired sensation due to diabetic neuropathy, commonly results in foot ulcerations. The subsequent development of infections is a major cause of morbidity in diabetics. Evaluation of diabetic foot infections often requires clinical, laboratory, microbiological and radiological assessment with bone imaging and MRI exhibiting the best sensitivity [85]. Osteomyelitis has a profound impact on the prognosis and management of these infections and the "gold standard" for its diagnosis remains the bone biopsy. Diabetic patients are five-times more likely than non-diabetic patients to undergo an amputation [82] and, moreover, diabetes is the leading cause of non-traumatic lower extremity amputations in the United States [48]. Atheromatous disease tends to affect more distal vessels such as the tibial and the peroneal arteries, producing multiple, diffuse lesions that are less straightforward to bypass or to dilate by angioplasty [83, 86, 87].

It has to be noted that a particular type of atherosclerosis called Mönckeberg's sclerosis can be observed in diabetic patients [88]. Mönckeberg's sclerosis is characterised by calcification of the medial wall, mainly of medium-sized and larger arteries, leading sometimes to an impressive image of a calcified artery network on X-rays. Although it was formerly believed to be an innocuous condition, it is now considered to be a variant of atherosclerosis with predominance of calcification and a small inflammatory component [89]. Calcification in the first dorsal metatarsal artery is common in Mönckeberg's sclerosis and, if seen on X-ray, is an indication for screening for the presence of DM [90].

Peripheral Doppler ultrasound has substituted for conventional angiography and digital subtraction angiography as the first line imaging technique for the diagnosis of PAD, while MR angiography is another non-invasive technique emerging into clinical practice [83, 91, 92]. Screening for subclinical PAD is strongly recommended in diabetic patients. Besides peripheral Doppler ultrasound, a widely used method in the evaluation of PAD in everyday practice is the ankle-brachial index $(\mathrm{ABI})$ test. $\mathrm{ABI}$ is calculated by dividing the systolic blood pressure measured at the level of the ankle by the systolic blood pressure measured in the brachial artery. As it is a simple, rapid, inexpensive, and reliable method of screening asymptomatic patients for PAD, the $\mathrm{ABI}$ test is ideal for implementation in the primary care physician's office [93]. An $\mathrm{ABI}<0.9$ is accepted as an indication of the presence of $\mathrm{PAD}$, while values $<0.5$ and $<0.3$ indicate severe disease and critical ischaemia respectively $[83,93]$. Values $>1.4$ may be associated with arterial incompressibility due to Mönckeberg's sclerosis, which can be seen in diabetic patients as well as in patients with chronic renal insufficiency. It has to be underlined that the early detection of PAD and the subsequent medical management is of great importance in preventing vascular morbidity and mortality of diabetic patients.

\section{Erectile dysfunction}

Erectile dysfunction is a common complication of diabetes, occurring in $\geq 50 \%$ of men with $\mathrm{DM}$, and DM is one of the greatest risk factors for erectile dysfunction [94]. Pathogen- 
esis is multifactorial, with autonomic neuropathy, vascular insufficiency and psychological factors contributing to the clinical picture [94, 95].

\section{Diabetes and infections}

Diabetes is associated with a greater frequency and severity of infections. Several abnormalities regarding the phagocyte function and cell-mediated immunity are implicated [96]. Skin, mucus, nails and soft tissues are frequently affected predominantly by staphylococcal and fungal infections, especially candidal infections. Pneumonia is caused by a similar spectrum of microorganisms as in the non-diabetic population, but with an over-representation of Staphylococcus aureus and Gram-negative bacteria such as Klebsiella pneumoniae $[15,96,97]$. Pneumococcal pneumonia occurs more commonly in the diabetic population and diabetics are also more susceptible to developing tuberculosis [96]. Lower tract urinary infections and pyelonephritis are common and they have as additional casual factors the presence of glucosuria and bladder dysfunction due to autonomic neuropathy. Diabetic foot infections are very common and can lead to serious consequences such as osteomyelitis and amputation.

Besides common infections, several less frequent infections are particularly associated with the presence of diabetes. These include emphysematous infections of the gall bladder and urinary tract, alithiasic cholecystitis, "malignant" or invasive otitis externa and the rare but frequently fatal rhinocerebral mucormycosis [15]. Finally, it has to be noted that diabetics are at greater risk of nosocomial (especially wound) infections [96].

\section{Conclusion}

DM is an epidemic disease. The increasing prevalence of obesity, especially that concerning childhood, as well as physical inactivity are mainly responsible for the increased incidence of DM. The prevalence of DM is expected to increase by $54 \%$ by 2030 . Future generations will be burdened with the complications of diabetes at the peak of their productivity. The multimorbidity of the diabetic population is increased due to the presence of acute and chronic complications and the high incidence of infections. The presence of hypertension and dyslipidaemia is common and increases the prevalence of CVD. Eighty percent of people with diabetes will die of CVD.

DM can affect almost every organ. The intersection of several types of complications increases the burden of the disease. The coexistence of micro- and macroangiopathy represents a major reason for the increased severity and the worst outcomes of CAD and PAD in diabetic patients. Microangiopathy further reduces vascularisation and impairs the development of collateral vessels in ischaemic tissues and thus amplifies the severity of macroangiopathy, promoting tissue hypoxia and reduced wound healing. Autonomic neuropathy also contributes to the impairment of cardiac function. Besides PAD and microangiopathy, diabetic polyneuropathy and the increased susceptibility to infections are other significant causal factors in the pathogenesis of the diabetic foot, which is a very common situation that is frequently difficult to treat. Diverse imaging techniques are in use in clinical practice and research. The contribution of these imaging studies is of great importance for the diagnosis and, more importantly, the early detection of diabetic complications, which is increasingly considered to be the hallmark of the treatment of diabetic patients.

\section{References}

1. International Diabetes Federation (2006) Diabetes atlas, 3rd edn. International Diabetes Federation, Brussels

2. American Diabetes Association (2010) Diagnosis and classification of diabetes mellitus. Diab Care 33(Suppl 1):S62-S69

3. Alberti KG, Zimmet PZ (1998) Definition, diagnosis and classification of diabetes mellitus and its complications. Part 1: diagnosis and classification of diabetes mellitus provisional report of a WHO consultation. Diabet Med 15:539-553

4. Alberti KG, Eckel RH, Grundy SM et al (2009) Harmonizing the metabolic syndrome: a joint interim statement of the International Diabetes Federation Task Force on Epidemiology and Prevention; National Heart, Lung, and Blood Institute; American Heart Association; World Heart Federation; International Atherosclerosis Society; and International Association for the Study of Obesity. Circulation 120:1640-1645

5. Shaw JE, Sicree RA, Zimmet PZ Global estimates of the prevalence of diabetes for 2010 and 2030. Diabetes Res Clin Pract 87:4-14

6. Prentice AM (2006) The emerging epidemic of obesity in developing countries. Int J Epidemiol 35:93-99

7. Ramachandran A, Snehalatha C, Latha E, Manoharan M, Vijay V (1999) Impacts of urbanisation on the lifestyle and on the prevalence of diabetes in native Asian Indian population. Diabetes Res Clin Pract 44:207-213

8. Franks PW, Hanson RL, Knowler WC, Sievers ML, Bennett PH, Looker HC (2010) Childhood obesity, other cardiovascular risk factors, and premature death. N Engl J Med 362:485-493

9. Schulze MB, Hoffmann K, Boeing H et al (2007) An accurate risk score based on anthropometric, dietary, and lifestyle factors to predict the development of type 2 diabetes. Diab Care 30:510-515

10. Bentley-Lewis R, Levkoff S, Stuebe A, Seely EW (2008) Gestational diabetes mellitus: postpartum opportunities for the diagnosis and prevention of type 2 diabetes mellitus. Nat Clin Pract Endocrinol Metab 4:552-558

11. Mooradian AD (2009) Dyslipidemia in type 2 diabetes mellitus. Nat Clin Pract Endocrinol Metab 5:150-159

12. Gress TW, Nieto FJ, Shahar E, Wofford MR, Brancati FL (2000) Hypertension and antihypertensive therapy as risk factors for type 2 diabetes mellitus. Atherosclerosis Risk in Communities Study. N Engl J Med 342:905-912 
13. Turnbull F, Neal B, Algert C et al (2005) Effects of different blood pressure-lowering regimens on major cardiovascular events in individuals with and without diabetes mellitus: results of prospectively designed overviews of randomized trials. Arch Intern Med 165:1410-1419

14. Roper NA, Bilous RW, Kelly WF, Unwin NC, Connolly VM (2001) Excess mortality in a population with diabetes and the impact of material deprivation: longitudinal, population based study. BMJ 322:1389-1393

15. Kahn CR, Weir GC, King GL, Moses AC, Smith RJ, Jacobson RM (2005) Joslin's Diabetes mellitus, 14th edn. Lippincott Williams \& Wilkins, Boston, pp 887-889

16. The Diabetes Control and Complications Trial Research Group (1993) The effect of intensive treatment of diabetes on the development and progression of long-term complications in insulin-dependent diabetes mellitus. The Diabetes Control and Complications Trial Research Group. N Engl J Med 329:977-986

17. UK Prospective Diabetes Study (UKPDS) Group (1998) Intensive blood-glucose control with sulphonylureas or insulin compared with conventional treatment and risk of complications in patients with type 2 diabetes (UKPDS 33). UK Prospective Diabetes Study (UKPDS) Group. Lancet 352:837-853

18. Viberti G, Keen H, Dodds R, Bending JJ (1987) Metabolic control and progression of diabetic nephropathy. Diabetologia 30:481-482

19. The National Institutes of Health. National Institute of Diabetes and Digestive and Kidney Diseases (1997) U.S. Renal Data System, USRDS Annual Data Report. The National Institutes of Health. National Institute of Diabetes and Digestive and Kidney Diseases, Bethesda

20. Held PJ, Port FK, Webb RL et al (1991) The United States Renal Data System's 1991 annual data report: an introduction. Am J Kidney Dis 18:1-16

21. Jerums G, Panagiotopoulos S, Premaratne E, MacIsaac RJ (2009) Integrating albuminuria and GFR in the assessment of diabetic nephropathy. Nat Rev Nephrol 5:397-406

22. Kahn CR, Weir GC, King GL, Moses AC, Smith RJ, Jacobson RM (2005) Joslin's Diabetes Mellitus 14th edn. Lippincott Williams \& Wilkins Boston, pp 853-866

23. Raptis AE, Viberti G (2001) Pathogenesis of diabetic nephropathy. Exp Clin Endocrinol Diabetes 109(Suppl 2):S424-S437

24. Association AD (2010) Standards of medical care in diabetes. Diab Care 33(Suppl 1):S11-S61

25. Lewis EJ, Hunsicker LG, Clarke WR et al (2001) Renoprotective effect of the angiotensin-receptor antagonist irbesartan in patients with nephropathy due to type 2 diabetes. N Engl J Med 345:851860

26. Parving HH, Lehnert $\mathrm{H}$, Brochner-Mortensen J, Gomis R, Andersen S, Arner P (2001) The effect of irbesartan on the development of diabetic nephropathy in patients with type 2 diabetes. N Engl J Med 345:870-878

27. Parving HH, Persson F, Lewis JB, Lewis EJ, Hollenberg NK (2008) Aliskiren combined with losartan in type 2 diabetes and nephropathy. N Engl J Med 358:2433-2446

28. Yusuf S, Sleight P, Pogue J, Bosch J, Davies R, Dagenais G (2000) Effects of an angiotensin-converting-enzyme inhibitor, ramipril, on cardiovascular events in high-risk patients. The Heart Outcomes Prevention Evaluation Study Investigators. N Engl J Med 342:145-153

29. Pomposelli F (2010) Arterial imaging in patients with lower extremity ischemia and diabetes mellitus. J Vasc Surg 52:81S-91S

30. Ghafour IM, Allan D, Foulds WS (1983) Common causes of blindness and visual handicap in the west of Scotland. Br J Ophthalmol 67:209-213

31. Porta M, Tomalino MG, Santoro F et al (1995) Diabetic retinopathy as a cause of blindness in the province of Turin, north-west Italy, in 1967-1991. Diabet Med 12:355-361
32. Porta M, Bandello F (2002) Diabetic retinopathy. A clinical update. Diabetologia 45:1617-1634

33. (1994) Microvascular and acute complications in IDDM patients: the EURODIAB IDDM Complications Study. Diabetologia $37: 278-285$

34. Harris MI, Klein R, Welborn TA, Knuiman MW (1992) Onset of NIDDM occurs at least 4-7 yr before clinical diagnosis. Diab Care $15: 815-819$

35. Boulton AJ, Vinik AI, Arezzo JC et al (2005) Diabetic neuropathies: a statement by the American Diabetes Association. Diab Care 28:956-962

36. Tesfaye S, Chaturvedi N, Eaton SE et al (2005) Vascular risk factors and diabetic neuropathy. N Engl J Med 352:341-350

37. Deshpande AD, Harris-Hayes M, Schootman M (2008) Epidemiology of diabetes and diabetes-related complications. Phys Ther 88:1254-1264

38. Rajbhandari SM, Jenkins RC, Davies C, Tesfaye S (2002) Charcot neuroarthropathy in diabetes mellitus. Diabetologia 45:1085-1096

39. Thrainsdottir IS, Aspelund T, Thorgeirsson G et al (2005) The association between glucose abnormalities and heart failure in the population-based Reykjavik study. Diab Care 28:612-616

40. Mak KH, Moliterno DJ, Granger CB et al (1997) Influence of diabetes mellitus on clinical outcome in the thrombolytic era of acute myocardial infarction. GUSTO-I Investigators. Global Utilization of Streptokinase and Tissue Plasminogen Activator for Occluded Coronary Arteries. J Am Coll Cardiol 30:171-179

41. Berry C, Brett M, Stevenson K, McMurray JJ, Norrie J (2008) Nature and prognostic importance of abnormal glucose tolerance and diabetes in acute heart failure. Heart 94:296-304

42. Kannel WB, Hjortland M, Castelli WP (1974) Role of diabetes in congestive heart failure: the Framingham study. Am J Cardiol 34:29-34

43. Asghar O, Al-Sunni A, Khavandi K et al (2009) Diabetic cardiomyopathy. Clin Sci (Lond) 116:741-760

44. Braunwald E (ed) (2001) Heart disease: a textbook of cardiovascular medicine, 6th edn. WB Saunders, Philadelphia, pp 2143-2144

45. Khavandi K, Khavandi A, Asghar O et al (2009) Diabetic cardiomyopathy - a distinct disease? Best Pract Res Clin Endocrinol Metab 23:347-360

46. Maya L, Villarreal FJ Diagnostic approaches for diabetic cardiomyopathy and myocardial fibrosis. J Mol Cell Cardiol 48: 524-529

47. Rijzewijk LJ, van der Meer RW, Smit JW et al (2008) Myocardial steatosis is an independent predictor of diastolic dysfunction in type 2 diabetes mellitus. J Am Coll Cardiol 52:1793-1799

48. Beckman JA, Creager MA, Libby P (2002) Diabetes and atherosclerosis: epidemiology, pathophysiology, and management. JAMA 287:2570-2581

49. Turner RC (1998) The U.K. Prospective Diabetes Study. A review. Diabetes Care 21(Suppl 3): C35-C38

50. Garcia MJ, McNamara PM, Gordon T, Kannel WB (1974) Morbidity and mortality in diabetics in the Framingham population. Sixteen year follow-up study. Diabetes 23:105-111

51. Bloomgarden ZT (2005) Clinical diabetic neuropathy. Diab Care 28:2968-2974

52. Krolewski AS, Warram JH, Rand LI, Kahn CR (1987) Epidemiologic approach to the etiology of type I diabetes mellitus and its complications. N Engl J Med 317:1390-1398

53. Huxley R, Barzi F, Woodward M (2006) Excess risk of fatal coronary heart disease associated with diabetes in men and women: meta-analysis of 37 prospective cohort studies. BMJ 332:73-78

54. Stamler J, Vaccaro O, Neaton JD, Wentworth D (1993) Diabetes, other risk factors, and 12-yr cardiovascular mortality for men screened in the Multiple Risk Factor Intervention Trial. Diab Care $16: 434-444$ 
55. Miettinen H, Lehto S, Salomaa V et al (1998) Impact of diabetes on mortality after the first myocardial infarction. The FINMONICA Myocardial Infarction Register Study Group. Diab Care 21:69-75

56. Malmberg K, Yusuf S, Gerstein HC et al (2000) Impact of diabetes on long-term prognosis in patients with unstable angina and non-Q-wave myocardial infarction: results of the OASIS (Organization to Assess Strategies for Ischemic Syndromes) Registry. Circulation 102:1014-1019

57. Herlitz J, Karlson BW, Lindqvist J, Sjolin M (1998) Rate and mode of death during five years of follow-up among patients with acute chest pain with and without a history of diabetes mellitus. Diabet Med 15:308-314

58. Haffner SM, Lehto S, Ronnemaa T, Pyorala K, Laakso M (1998) Mortality from coronary heart disease in subjects with type 2 diabetes and in nondiabetic subjects with and without prior myocardial infarction. N Engl J Med 339:229-234

59. Expert Panel on Detection, Evaluation, and Treatment of High Blood Cholesterol in Adults(2001) Executive Summary of The Third Report of The National Cholesterol Education Program (NCEP) Expert Panel on Detection, Evaluation, And Treatment of High Blood Cholesterol In Adults (Adult Treatment Panel III). JAMA 285:2486-2497

60. Grundy SM, Cleeman JI, Merz CN et al (2004) Implications of recent clinical trials for the National Cholesterol Education Program Adult Treatment Panel III guidelines. Circulation 110:227-239

61. Detre KM, Lombardero MS, Brooks MM et al (2000) The effect of previous coronary-artery bypass surgery on the prognosis of patients with diabetes who have acute myocardial infarction. Bypass Angioplasty Revascularization Investigation Investigators. N Engl J Med 342:989-997

62. Elezi S, Kastrati A, Pache J et al (1998) Diabetes mellitus and the clinical and angiographic outcome after coronary stent placement. J Am Coll Cardiol 32:1866-1873

63. Budoff MJ, Achenbach S, Blumenthal RS et al (2006) Assessment of coronary artery disease by cardiac computed tomography: a scientific statement from the American Heart Association Committee on Cardiovascular Imaging and Intervention, Council on Cardiovascular Radiology and Intervention, and Committee on Cardiac Imaging, Council on Clinical Cardiology. Circulation 114:1761-1791

64. Greenland P, Bonow RO, Brundage BH et al (2007) ACCF/AHA 2007 clinical expert consensus document on coronary artery calcium scoring by computed tomography in global cardiovascular risk assessment and in evaluation of patients with chest pain: a report of the American College of Cardiology Foundation Clinical Expert Consensus Task Force (ACCF/AHA Writing Committee to Update the 2000 Expert Consensus Document on Electron Beam Computed Tomography). Circulation 115:402-426

65. Stirban AO, Tschoepe D (2008) Cardiovascular complications in diabetes: targets and interventions. Diab Care 31(Suppl 2):S215S221

66. You RX, McNeil JJ, O'Malley HM, Davis SM, Thrift AG, Donnan GA (1997) Risk factors for stroke due to cerebral infarction in young adults. Stroke 28:1913-1918

67. Jorgensen H, Nakayama H, Raaschou HO, Olsen TS (1994) Stroke in patients with diabetes. The Copenhagen Stroke Study. Stroke 25:1977-1984

68. Luchsinger JA, Tang MX, Stern Y, Shea S, Mayeux R (2001) Diabetes mellitus and risk of Alzheimer's disease and dementia with stroke in a multiethnic cohort. Am J Epidemiol 154:635641

69. U-King-Im YV, Gillard JH (2009) Carotid-artery imaging in the diagnosis and management of patients at risk of stroke. Lancet Neurol 8:569-580
70. Biasi GM, Froio A, Diethrich EB et al (2004) Carotid plaque echolucency increases the risk of stroke in carotid stenting: the Imaging in Carotid Angioplasty and Risk of Stroke (ICAROS) study. Circulation 110:756-762

71. Kwee RM, van Oostenbrugge RJ, Hofstra L et al (2008) Identifying vulnerable carotid plaques by noninvasive imaging. Neurology 70:2401-2409

72. Marso SP, House JA, Klauss V, Lerman A, Margolis P, Leon MB; Global VH-IVUS (2010) Diabetes mellitus is associated with plaque classified as thin cap fibroatheroma: an intravascular ultrasound study. Diab Vasc Dis Res 7:14-19

73. Lane HA, Smith JC, Davies JS (2006) Noninvasive assessment of preclinical atherosclerosis. Vasc Health Risk Manag 2:19-30

74. Su Y, Liu XM, Sun YM, Wang YY, Luan Y, Wu Y (2008) Endothelial dysfunction in impaired fasting glycemia, impaired glucose tolerance, and type 2 diabetes mellitus. Am J Cardiol 102:497-498

75. Mancia G, De Backer G, Dominiczak A et al (2007) 2007 ESHESC Practice Guidelines for the Management of Arterial Hypertension: ESH-ESC Task Force on the Management of Arterial Hypertension. J Hypertens 25:1751-1762

76. O'Leary DH, Polak JF, Kronmal RA, Manolio TA, Burke GL, Wolfson SK Jr (1999) Carotid-artery intima and media thickness as a risk factor for myocardial infarction and stroke in older adults. Cardiovascular Health Study Collaborative Research Group. N Engl J Med 340:14-22

77. Lorenz MW, Markus HS, Bots ML, Rosvall M, Sitzer M (2007) Prediction of clinical cardiovascular events with carotid intimamedia thickness: a systematic review and meta-analysis. Circulation 115:459-467

78. Brohall G, Oden A, Fagerberg B (2006) Carotid artery intimamedia thickness in patients with Type 2 diabetes mellitus and impaired glucose tolerance: a systematic review. Diabet Med 23:609-616

79. Sharma K, Blaha MJ, Blumenthal RS, Musunuru K (2009) Clinical and research applications of carotid intima-media thickness. Am J Cardiol 103:1316-1320

80. Nguyen-Thanh HT, Benzaquen BS (2009) Screening for subclinical coronary artery disease measuring carotid intima media thickness. Am J Cardiol 104:1383-1388

81. Newman AB, Siscovick DS, Manolio TA et al (1993) Ankle-arm index as a marker of atherosclerosis in the Cardiovascular Health Study. Cardiovascular Heart Study (CHS) Collaborative Research Group. Circulation 88:837-845

82. Jude EB, Oyibo SO, Chalmers N, Boulton AJ (2001) Peripheral arterial disease in diabetic and nondiabetic patients: a comparison of severity and outcome. Diab Care 24:1433-1437

83. Jude EB, Eleftheriadou I, Tentolouris N (2009) Peripheral arterial disease in diabetes - a review. Diabet Med 27:4-14

84. Criqui MH, Langer RD, Fronek A et al (1992) Mortality over a period of 10 years in patients with peripheral arterial disease. $\mathrm{N}$ Engl J Med 326:381-386

85. Berendt AR, Peters EJ, Bakker K et al (2008) Diabetic foot osteomyelitis: a progress report on diagnosis and a systematic review of treatment. Diabetes Metab Res Rev 24(Suppl 1):S145S161

86. Faglia E, Clerici G, Clerissi J et al (2006) Early and five-year amputation and survival rate of diabetic patients with critical limb ischemia: data of a cohort study of 564 patients. Eur J Vasc Endovasc Surg 32:484-490

87. van der Feen C, Neijens FS, Kanters SD, Mali WP, Stolk RP, Banga JD (2002) Angiographic distribution of lower extremity atherosclerosis in patients with and without diabetes. Diabet Med 19:366-370

88. Fishbein GA, Fishbein MC (2009) Arteriosclerosis: rethinking the current classification. Arch Pathol Lab Med 133:1309-1316 
89. McCullough PA, Agrawal V, Danielewicz E, Abela GS (2008) Accelerated atherosclerotic calcification and Monckeberg's sclerosis: a continuum of advanced vascular pathology in chronic kidney disease. Clin J Am Soc Nephrol 3:1585-1598

90. Smith CD, Bilmen JG, Iqbal S, Robey S, Pereira M (2008) Medial artery calcification as an indicator of diabetic peripheral vascular disease. Foot Ankle Int 29:185-190

91. Dyet JF, Nicholson AA, Ettles DF (2000) Vascular imaging and intervention in peripheral arteries in the diabetic patient. Diabetes Metab Res Rev 16(Suppl 1):S16-S22

92. Lapeyre M, Kobeiter H, Desgranges P, Rahmouni A, Becquemin JP, Luciani A (2005) Assessment of critical limb ischemia in patients with diabetes: comparison of MR angiography and digital subtraction angiography. AJR Am J Roentgenol 185:1641-1650
93. Al-Qaisi M, Nott DM, King DH, Kaddoura S (2009) Ankle brachial pressure index (ABPI): An update for practitioners. Vasc Health Risk Manag 5:833-841

94. Thorve VS, Kshirsagar AD, Vyawahare NS, Joshi VS, Ingale KG, Mohite RJ (2010) Diabetes-induced erectile dysfunction: epidemiology, pathophysiology and management. J Diabetes Complications http://dx.doi.org/10.1016/j.jdiacomp.2010.03.003

95. Tamler R (2009) Diabetes, obesity, and erectile dysfunction. Gend Med 6(Suppl 1):4-16

96. Peleg AY, Weerarathna T, McCarthy JS, Davis TM (2007) Common infections in diabetes: pathogenesis, management and relationship to glycaemic control. Diabetes Metab Res Rev 23:3-13

97. Joshi N, Caputo GM, Weitekamp MR, Karchmer AW (1999) Infections in patients with diabetes mellitus. $\mathrm{N}$ Engl $\mathrm{J}$ Med 341:1906-1912 